
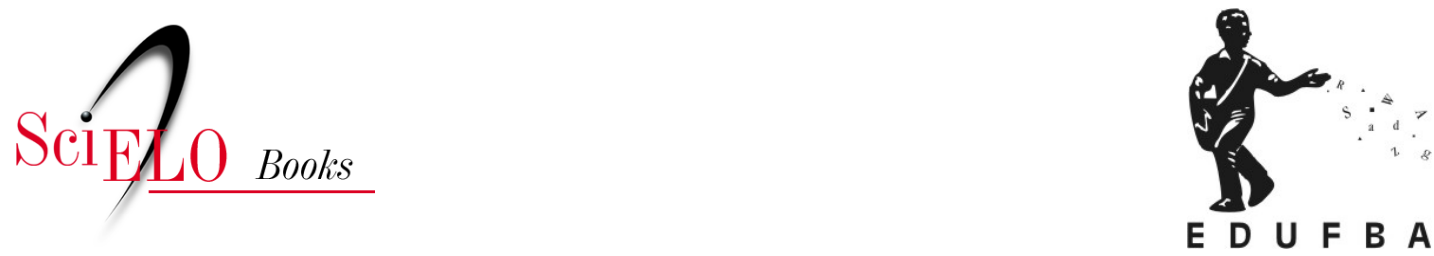

\title{
Conclusão: por uma gestão solidária, sustentável e em comum
}

\author{
Genauto Carvalho de França Filho \\ Philippe Eynaud
}

\section{SciELO Books / SciELO Livros / SciELO Libros}

FRANÇA FILHO, G. C., and EYNAUD, P. Conclusão: por uma gestão solidária, sustentável e em comum. In.: Solidariedade e organizações: pensar uma outra organização [online]. Salvador: EDUFBA; Ateliê de Humanidades, 2020, pp. 265269. ISBN: 978-65-5630-199-0. https://doi.org/10.7476/9786556301990.0006.

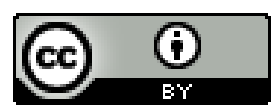

All the contents of this work, except where otherwise noted, is licensed under a Creative Commons Attribution 4.0 International license.

Todo o conteúdo deste trabalho, exceto quando houver ressalva, é publicado sob a licença Creative Commons Atribição 4.0.

Todo el contenido de esta obra, excepto donde se indique lo contrario, está bajo licencia de la licencia Creative Commons Reconocimento 4.0. 


\title{
Conclusão: por uma gestão solidária, sustentável \\ e em comum
}

\begin{abstract}
"Sozinho, em sua fragilidade, o verbo pode reunir a multidão de homens para que a onda de violência se transforme em uma reconstrução amigável". (ILLICH, 1973, p. 157)

"A utopia não é o impossível, mas o não realizado".
\end{abstract}

(MONOD, 2007, p. 211)

Diante das urgências levantadas pelas evoluções de nosso mundo, este livro teve por ambição questionar as relações entre solidariedade e organizações para tentar pensar uma outra gestão. Um retorno à história do pensamento nos mostrou que, embora a administração tenha falhado em manter a solidariedade como princípio norteador, ela sempre esteve subjacente à conceitualização da gestão. No entanto, o peso do modelo anglo-saxão na disciplina tem de certa forma invizibilizado, até recentemente, tudo o que não se encaixa nos pressupostos de uma economia de mercado. É assim que gerações de estudantes aprenderam que a administração visa ao desempenho organizacional em uma perspectiva de maximização de lucro. A gestão formal parece se desenrolar em "um mundo sem contradição porque sem profundidade". (BARTHES, I970, p. 253) Essa instrumentalização da gestão em um contexto de mercado, por sua vez, favoreceu as abordagens calculistas e desqualificou 
as questões mais políticas levantadas na introdução deste livro como as desigualdades e as problemáticas a mbientais. A generalização do contrato em todas as áreas da vida profissional e pessoal teve uma dimensão profundamente "insolidária”. (CHAUVIÈRE, 2007, p. 55) Devido ao seu caráter hegemônico, a história do pensamento sobre a gestão e os modelos associados relegaram de certo modo as experiências vindas de outras áreas geográficas e culturais em zonas periféricas do saber, quando não as ocultaram.

No entanto, há uma história desconhecida da relação entre solidariedade e organizações. Podemos segui-la através da história das organizações da economia social e solidária. Estas últimas devem muito às suas invenções em termos de gestão e às suas inovações organizacionais que a história, entretanto, não reteve enquanto tais. Uma releitura da história da gestão à luz dessas organizações ainda precisa ser feita. Ela permitiria trazer à tona os atores esquecidos e/ou desqualificados nessas questões organizacionais. Entre eles, os autores da corrente associacionista, evidentemente, mas também toda a história das culturas ancestrais dos povos do sul, cujos processos organizacionais foram marcados pela relação com a solidariedade. Essa narrativa não é fácil de construir, porque grande parte dessa memória reside na cultura oral. Nesse sentido, o desvio pelas histórias do sul é indispensável para a formação do conhecimento básico, conforme salientou Mauss (2007). Para superar o obstáculo do que pode parecer como um inconsciente das teorias da organização, esse trabalho histórico crítico nos parece indispensável se queremos reabilitar e desenvolver a questão organizacional e econômica em um contexto social e de cidadania. É preciso considerar que os meios podem transformar os fins, e até subvertê-los. Exemplos de derivas são numerosos: "buscar dinheiro por dinheiro, cultivar poder por ele mesmo ou conquistar o poder para gozar de autoridade". (CHABOT, 2015, p. 52) Em um mundo que se tornou técnico, a vigilância em termos de escolhas organizacionais é mais necessária do que nunca. Essa vigilância pode ser alimentada cultivando o sentido que às vezes falta na gestão. Parafraseando Rabelais, Naro observa ironicamente "que eficiência sem consciência é apenas perda de sentido". (NARO, 20I5, p. 169) 
Neste livro, exploramos dois caminhos. O primeiro nos levou da organização à solidariedade. Mostramos que a organização da solidariedade não pode fazer economia de um questionamento sobre a definição de economia. A referência à abordagem polanyiana nos permitiu lançar as bases de uma gestão substantiva que pudesse considerar como princípios a reciprocidade, a redistribuição e o compartilhamento doméstico, juntamente com a troca de mercado. É assim que estudamos a possibilidade para este tipo de gestão de se envolver num processo de reintegração das mercadorias fictícias. Vimos com Guerreiro Ramos que uma decisão de gestão pode ser baseada em uma racionalidade substantiva, ou seja, em uma racionalidade de valor (WEBER, I97I), e que é necessário repensar a questão do tempo e do espaço para esperar abrir perspectivas sobre uma nova teoria das organizações. O pensamento de Guerreiro Ramos completa, assim, o trabalho iniciado por Polanyi e o prolonga, questionando os fundamentos da teoria das organizações.

O segundo caminho que o livro procurou explorar se baseia na perspectiva inversa: nos interrogamos sobre os meios de solidarizar a organização. Nesse sentido, a análise fez surgir questões relacionadas à solidariedade democrática. Para compensar os mecanismos corporatistas de fechamento comunitário (GIRARD, 1983), a gestão solidária pode ser lida através da abertura da governança das organizações de múltiplas partes interessadas ou na inclusividade da sua abordagem. Assim, ela conduz à tomada de decisão e a avaliação coletiva. Ela reúne os atores relevantes de um determinado território e abre para a gestão de proximidade. (BACQUÉ; REY; SINTOMER, 2005) Essa tarefa complexa só pode ser resolvida com a hibridação de recursos, a coconstrução e a inscrição da organização em ação pública a serviço do interesse geral. Portanto, as questões que se colocam são de governança democrática, territórios solidários, reconciliação do econômico e do social e de inovação social.

Assim conectados, os dois conceitos de solidariedade e organizações são os vetores de uma outra gestão. Esta última encontra expressão em duas escolas de pensamento particularmente interessantes e que se distinguem pelo 
ponto de partida. Na filiação indireta dos trabalhos iniciados na década de 1950 por Guerreiro Ramos, a escola brasileira define as dimensões de uma gestão social aberta por meio de uma redefinição da economia e uma democratização das organizações. Essas não estão fechadas em si mesmas, mas consideradas em sua relação com a esfera pública. Elas são igualmente apreendidas na intersubjetividade de suas partes envolvidas, garantidora assim de sua possibilidade de emancipação. Em termos de gestão sustentável, os trabalhos da escola de Ostrom são particularmente relevantes pois se iniciaram com o tema da preservação de bens comuns naturais. A força dessa corrente de pensamento tem sido não parar por aí e abrir a questão dos bens comuns a outros recursos que não os naturais. A fusão analítica com os atores do software livre permitiu a esse referencial teórico, em particular, desenvolver uma reflexão preciosa sobre a auto-organização e a gestão de novas formas de propriedade coletiva em conexão com o digital. (EYNAUD; SULTAN, 2OI4; BROCA, 2OI7) Longe de serem concorrentes, essas duas escolas de pensamento são complementares e suas abordagens congruentes. Ambas compartilham a ideia de que a equação econômica não pode ser reduzida a uma dicotomia mercado-Estado, vislumbrando a possibilidade de um empreendedorismo coletivo e abrindo a perspectiva de uma solidariedade aberta, emancipatória e democrática.

Uma interrogação sobre os vínculos conjugados de solidariedade e organização parece um bom presságio de mudança significativa para os pesquisadores em teoria das organizações. De fato, "ao reconhecer o papel dos fenômenos organizacionais na construção do mundo, cabe aos pesquisadores repensar a ética da atividade coletiva". (DE VAUJANY; HUSSENOT; CHANLAT; 20I6, p. 20) e "propor modelos organizacionais e de gestão mais respeitosos dos seres humanos". (CHANLAT 2013, p. I8) Essa nova ética implica outras metodologias, outras posturas epistemológicas e, sem dúvida, outras articulações entre pesquisadores e atores do campo. Isso exige uma teoria crítica renovada suscetível de revelar "as emergências transbordando o mercado e o Estado". (LAVILLE, 20I5, p. 428) Esse esforço participa de um novo olhar sobre as emergências. Como sugere Sousa Santos, uma sociologia das ausências 
pode operar na ordem dos saberes "substituindo as monoculturas pelas ecologias". (SOUSA SANTOS, 2016, p. 257)

A exemplo da permacultura que articula agricultura e permanência, precisamos construir uma "permagestão" - permanagement -, associando gestão e sustentabilidade. No plano político, a urgência está aí. Diante do catastrofismo anunciado, devemos aceitar nossos limites (BEUE et al., 2017) e pousar em algum lugar. (LATOUR, 20I7) Como temos apenas um planeta, a defesa da biodiversidade e da sociodiversidade deve ser considerada como a única e mesma luta. De fato, um vínculo essencial e profundo "torna solidária as transições energéticas e democráticas". (CHABOT, 2015, p. I35) Diante da ameaça de um apocalipse tecnocrático, podemos opor a sociedade convivial. (CAILLÉ; HUMBERT; LATOUCHE; VIVERET, 2OII; ILLICH, I973; MANIFESTE CONVIVIALISTE, 20I3) Diante da hegemonia do modelo da empresa mercantil e do seu individualismo amoral, podemos fazer a escolha da organização democrática e prestar uma atenção renovada às formas organizacionais solidárias. 